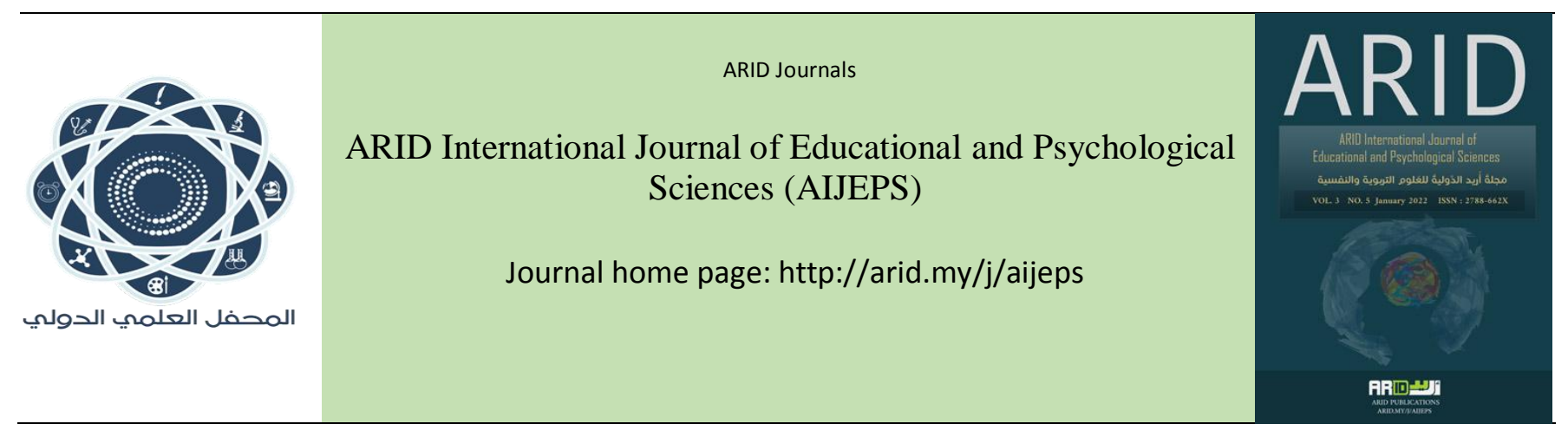

$$
\text { مَجلةُ أُريد الدَّوليةُة للعُلومِ التريوية والتفسية }
$$

\title{
Perceptions of non-native speakers of Arabic language towards cloud-based educational activities based on the entrance of multiple intelligences.
}

\section{تصوّرات متعلّمي اللّفة العربيّة النّاطقين بغيرها نحو الأنشطة التّعليميّة الستحابيّة القائمة على مدخل الذّكاعات المتعدّدة}

$$
\begin{aligned}
& \text { نهى عبد الكريم حسين } \\
& \text { المعهد العالي للّغات - جامعة دمثقـ- الجمهورية العربيّة السّوريّة } \\
& \text { نور أحمد سبانو }
\end{aligned}
$$

Learn Arabic with Nour 


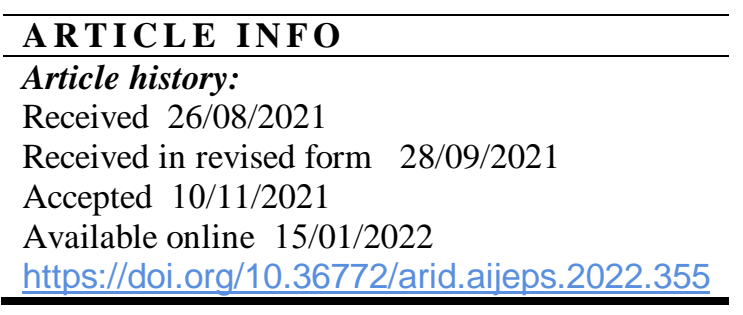

\begin{abstract}
The need to diversify educational cloud activities arose due to social distancing, the widening of individual differences between learners, and the need to employ the possibilities offered by cloud education to achieve language goals.

This research identifies the perceptions of non-native Arabic language learners towards the cloud-based educational activities based on the entrance of multiple intelligences.

The descriptive approach was used, and a questionnaire was designed, consisting of: (Linguistic, Musical, visual- Spatial, Interpersonal, and Interpersonal). The sample consisted of (33) male and female students.

The results showed that learners' perceptions are highly positive on all areas of activities. The highest percentage was interpersonal intelligence activities. Also, there are no statistically significant differences due to the sex.

The originality of the research presents a vision of the entrance of multiple intelligences; To benefit from its educational applications in teaching Arabic online to non-native speakers, and to keep pace with global trends in the adoption of cloud education and its activities. It is also expected that the results of this research will benefit the following groups: institutions concerned with teaching foreign languages, experts who prepare curricula for teaching Arabic, and teachers of Arabic for non-native speakers.

key words: Multiple Intelligences - Learning Activities - Cloud Learning - Teaching Arabic to Speakers of Other Languages - Effective Learning.
\end{abstract}




\section{الملخص}

هدف البحث تعرّف تصوّر ات مُتحلّمي اللّخة العربيّة النّاطقين بغير ها نحو الأنشطة التّعليميّة السّحابيّة القائمة على مدخل الذّكاءات

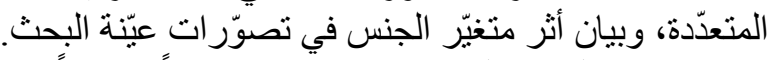

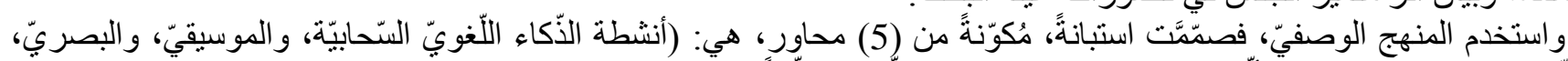

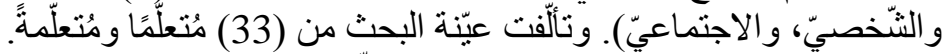

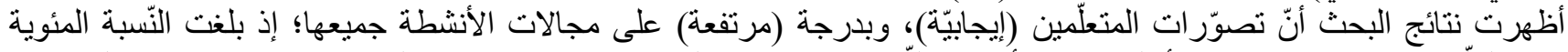

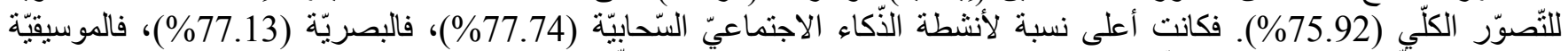

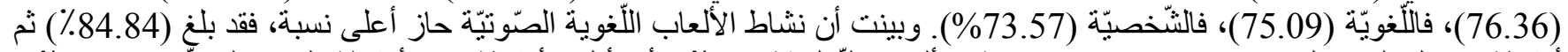

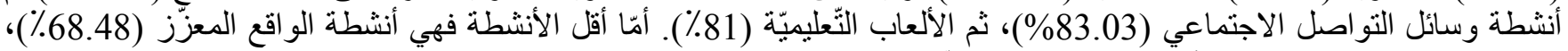

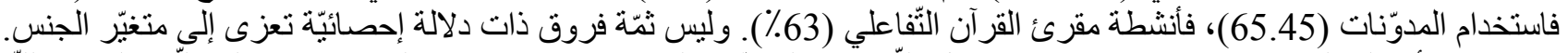

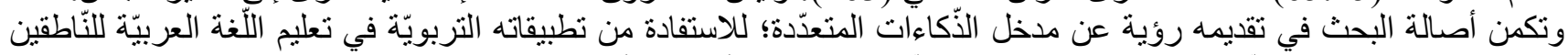

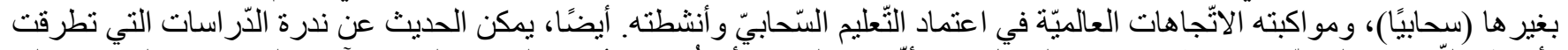

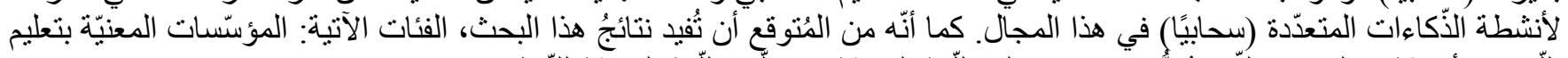

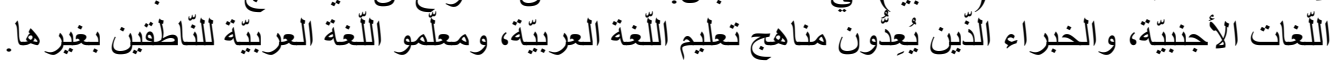

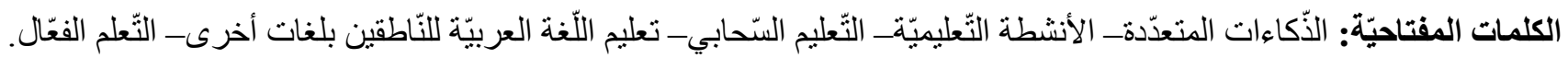




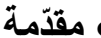

تنامى الاهتمام في تعليم اللّخة العربيّة للنّاطقين بغير ها سحابيًا، ممّا أدّى إلىى تغيّر في ماهية التّعليم ومضامينه، وأدوار المعلّم و المتعلّم، و الطّر ائق، والأنشطة، والمحتوى.

مدار الحديث هنا على الأنشطة النّّليميّة السّحابيّة؛ بوصفها جزءًا من المنهج الإلكترونيّ، ومصدرًا من مصادر تعلّم اللّّة العربيّة عزّزت الجائحةُ الحاجة إليها وتتويعها؛ لأنّ التّماسك الاجتماعيّ زاد الفروق الفرديّة انّضاحًا ممّا جعل الاستفادة من الإمكانات السّحابيّة ضرورة لا ترفًا. علاوة على ذلك، في العناية بها استجابة للتّطوّرات العالميّة في مجال المعلومات والاتّصالات، ومواكبة للاتّجاهات الحديثة في تعليم اللّغات الأجنيّّة وتعلّمها خلال الجوائح، ولكونها توفّر سياقًا حقيقًا وتجربة نقافيّة ومعلومات في الوقت نفسه، كما تمدّ

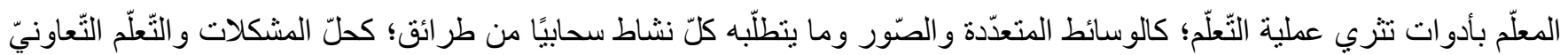
وسرد القصص...، ومن تمركزها حول المتعلّم، وجعلها التّعلّم تفاعليًا متحرّرًا من الزّمان و المكان وملبيًا للحاجات التّي تقتضيها الفروق الفرديّة و الميول المختلفة، إضافة إلى جاذبيتها بالنّسبة إلى المتعلّمين فهي تتناسب مع العصر الرّقميّ الّذي يعيشون فيه. من هنا، كانت مدخل الذّكاءات المتعدّدة ناهضةً بذلك كلّه. ذللك أنّه قائم على "فلسفة تربويّة مُعاصرة، أساسها المُتعلّم الذي يتميّز بذكاء مُكوّن من أبعادٍ مختلفة يجب أن يُعنرف بها وأن تُطوّر في التعليم" (رينشارد، 2005، ص5) ويُعدّ نموذجًا تربويًا رفيعَ المُستوى يُقّدم للتربويين مخططًا تربويًا يستطيعون على أساسه تطبيق ما يتعلق به من مبادئ، وأسس، ومواقف تعليميّة وتربويّة متعدّدة؛ لخلق فكرٍ جديدٍ يُسهم في النّّمية الذّاتية للفرد على نحو يسمح له بتعدّد القدرات التي تعينه على مواكبة تحدّيات العصر، والتأقلم مع الظّروف المحيطة بتدريس اللّغات الأجنبية، و الوصول إلى أعلى معدلات التعلّم المعرفيّ، و المهار اتيّ بأساليب محدّدة وأنشطة خاصة؛ لإكساب المُتعلّمين اللّغة الهدف؛ أبيّ العربيّة. ينطلق مؤسّس الذّكاء الكُتعدّد الأوجه هوارد جاردنر Howard Gardner H على الأقل ثمانية أنواع من الذّكاء أو القدرات، هي: الذّكاء اللُّويّ (اللّفظيّ)، والذّكاء المكانيّ (البصريّ)، و الذّكاء الموسيقيّ (السّمعيّ)، و الذّكاء الحركيّ (الجسديّ)، و الذّكاء الثّخصيّ، و الذّكاء الاجتماعيّ، و الذّكاء الطّبيعيّ (البيئيّ)، و الذّكاء المنطقيّ (الرّياضيّ). لكن بنسب متفاوتة. كما أنّ "النّظرة للذّكاء على أنّه أمر متعدّد الوجوه والأشكال لا توسّع النظرة لما عليه قدرات الإنّسان فحسب، بل توسّع النظرة إلى المتعلّم نفسه؛ ففي المفهوم التقليديّ للذّكاء ليس هناك تفسير واضح للنجاح في تعلّم اللّغة الثانية؛ لأنبّا نعرف أنّ هنالك بعض الأشخاص ممّن كان ذكاؤهم مرتفعًا وآخرين ممَّن كان ذكاؤ هم منخفضًا أثنتوا نجاحهم في التّعلّم. بيد أنَّ جاردنر يقدّم معطيات أخرى حول مفهوم التعلّم لها أهمية قصوى في تعلّم اللّغة الثّانية؛ فالذكاء الموسيقيّ يمكن أنْ يفسّر السّهولة النّسبيّة لفهم الأنماط التّنغيميّة للّّة و إنتاجها. و الذّكاء الحسيّ الحركيّ يمكن أن يفسّر تعلّم الأصوات اللّغوية بسهولة ... " (دوجلاس، 1994، ص132) ويُعين هذا المدخل مُعلّم اللّغة Abdul-Khafaji, العربيّة للنّاطقين بلغات أخرى إذا ما أراد تطبيقه على النّعامل مع طلّبه و إمكاناتهم في كلّ ذكاءٍ على انفراد، 


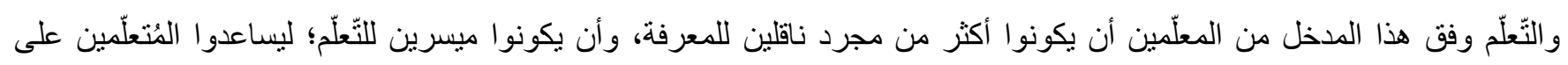
تطوير مسؤوليتهم نحو تعلّمهم". (جابر، 2003، ص113) ولكلّ نوع من هذه الذّكاءات أنشطةٌ تعليميّة ثُلائمه.

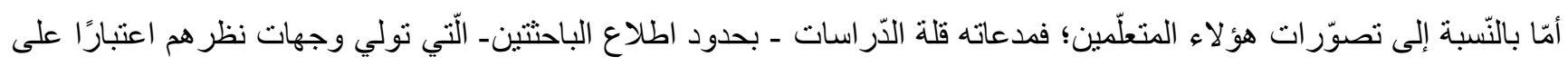
أهمّية ذلك؛ فمن خلالهم يمكن تعرف مخرجات هذه الأنشطة السّحابيّة القائمة على مدخل الذّكاءات المتعدّدة كما يلمسونها، ولكونهم معينًا على تحديد المناسب لهم منها. هذا من شأنه أن يجعل اختيار ها وتطوير ها منطلقًا من حاجاتهم الحقيقيّة.

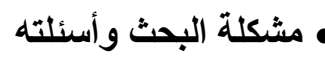

بدأت من تجربة الباحثة سبانو الثَّضيّة؛؛ إذ استخدمت بعض الأنشطة التُّليميّة السّحابيّة القائمة على مدخل الذّكاءات المتعدّدة

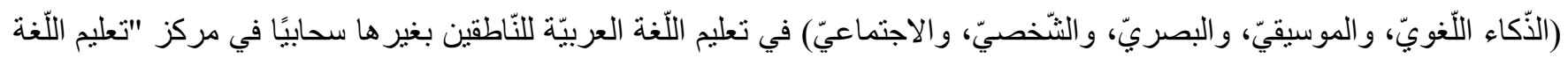
العربيّة مع نور learn Arabic with Nour"؛ ممّا أتاح لها نعرّف مخرجاتها في أثناء التّعليم ورغبتها في تعرّف تصوّرات المتعلّمبين من هذه الأنشطة. أيضًا، لأهمّية الأنشطة النّحابيّة حسب أبو عمشة وآخرين (2020)؛ فهي تمثّل نهجًا متكاملًا من التّعليم يجمع بين تتمية المهار ات، وتطوير العلاقات الاجتماعيّة (التّو اصل)، ومو اكبة المستحدثات الرّقَميّة. ولكونها تحقّق مبادئ عدّة، هي: "الإتاحيّة، والمرونة، وتحكّم المتعلّم، واختيار أنظمة التّوصيل، والاعتماديّة" (صيام، والعبد الله، وديب 2010، ص238). واستنادًا إلى توصيات "المنتدى الدّوليّ الافتر اضيّ للَّة العربيّة للنّاطقين بغير ها بعد كوفيد 19: تجديد الإستر اتيجيات وتطوير الوسائل والمنهجيات" (2020) بضرورة تفعيل المستحدثات الرّقيّة في تعليميّة اللّغة خلال الجوائح لا سيّما أنّ هناك قصورًا في نوظيفها على نحو عام من قبل؛ إذ "لا ينعدّى

$$
\text { الاستخدام الحقيقيّ كونه محاو لات خجولة، ودون المنتظر منه" (عبد الله، 2016، ص131). }
$$

و انطلاقًا من أهيّة مدخل الذّكاءات المتعدّدة في تعليم اللّغة العربيّة للنّاطقين بغيرها؛ ذلك أنّ اتبّاع الأساليب الحديثة والاتجاهات المعاصرة في التّعليم من شأنه أن برتقي بمستوى المُتعلّمين فيها. كما أنّ دراسة حسين (2017) أظهرت اتَّاهًا إيجابيًا من معلّمي اللَّغة العربيّة للنّاطقين بغير ها نحو بناء الأنشطة التّليميّة القائمة وفق الذّكاءات المتعدَدة. وقد عزت دراسة رمضان وآخرين (2018) ضعف المتعلّمين في مهارات اللّفة العربيّة إلى أسباب عدّة، منها: غياب الأنثطة

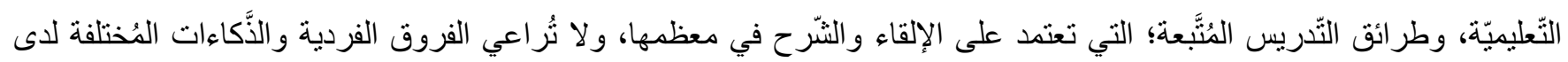

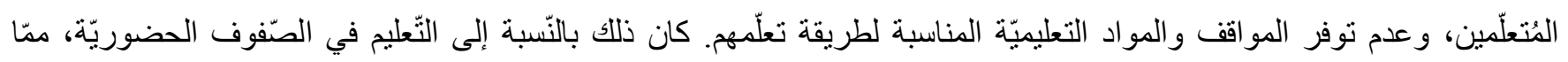
استدعى انتباه الباحثتين إلى أنّ هذه الأسباب قد تكون نفسها في التّعليم الإلكترونيّ. فاتَّجها إلى تعرّف تصوّرات متعلّمي اللّذة العربيّة النّاطقين بغير ها نحو الأنشطة النّعليميّة السّحابيّة القائمة على مدخل الذَّاءات المتعدَّة. تبعًا لذلك تكمن مشكلة البحث في الإجابة عن السيؤال الرَّئيس الآتي: 
ما تصوّرات متعلّمي اللّفة العربيّة النّاطقين بغيرها نحو الأنثطة التّعليميّة الستحابيّة القائمة على مدخل الأّكاءات المتعدّدة؟ وتتفر ع عنه الأسئلة البحثيّة الآتية:

1. ما تصوّرات متعلّمي اللّفة العربيّة النّاطقين بغيرها نحو الأنثطة التّعليميّة الستحابيّة القائمة على الأّكاء اللّفوي؟ 2. ما تصوّرات متعلّمي اللّفة العربيّة النّاطقين بغيرها نحو الأنثطة التّعليميّة الستحابيّة القائمة على الذّكاء الموسيقيّ؟ 3. ما تصوّرات متعلّمي اللّفة العربيّة النّاطقين بغيرها نحو الأنشطة التّعليميّة الستحابيّة القائمة على الذّكاء البصريّ؟ 4. ما تصوّرات متعلّمي اللّفة العربيّة النّاطقين بغيرها نحو الأنشطة التّعليميّة الستحابيّة القائمة على الذّكاء الثثّتصي؟ 5. ما تصوّرات متعلّمي اللّفة العربيّة النّاطقين بغيرها نحو الأنشطة التّعليميّة السّحابيّة القائمة على الأّكاء الاجتماعيّ؟ 6. هل ثمّة فروق بين تصوّرات هؤلاء المتعلّمين تعزى إلى متغيّر الجنس؟

$$
\text { • أهداف البحث }
$$

1. تعرّف ما تصوّر ات متعلّمي اللّّة العربيّة النّاطقين بغير ها نحو الأنشطة التّعليميّة السّحابيّة القائمة على مدخل الذّكاءات المتعدّدة. 2. بيان أثر متغيّر الجنس في تصوّرات هؤ لاء المتعلّمين. • أهمّية البحث

$$
\text { 1. جدّة الموضوع بحدود اطلاع الباحثتين. }
$$

2. تحديد الأنشطة التّعليميّة الستحابيّة القائمة على مدخل الذّكاءات المتعدّدة المناسبة لمتعلّمي اللّغة العربيّة النّاطقين بغير ها، من وجهة نظر هم.

3. مو اكبته الاتّجاهات الحديثة في مجال تعليم اللّغات الأجنيّة وتعلّمها التّي دعت إلى العناية بالأنشطة التّعليميّة السّحابيّة في إكساب

$$
\text { 4المهار ات وتنميتها سحابيًا لا سيّما خلال الجوائح. }
$$

5. يمكن أن تفيد نتائجه المؤسّسات المعنيّة بتعليم اللّّة العربيّة للنّاطقين بغيرها، ومعلّميها سحابيًا، والخبراء الّّنين يعدّون مناهجها

النّّليميّة و التّأهيليّة. 


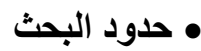

1. الحدود الزَّمانية: أُجري البحث في شهري أبريل ومايو، من العام 2021.

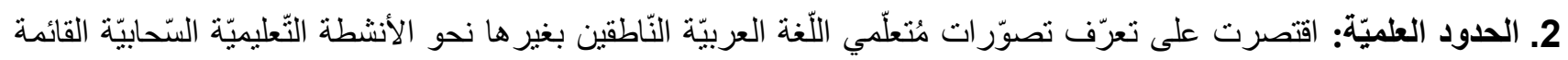

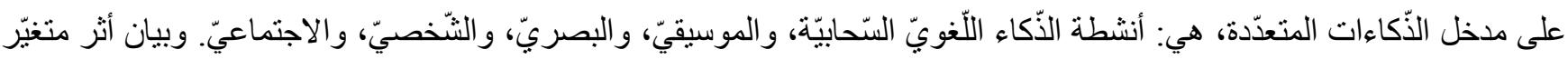
الجنس في تصوّرات عيّنة البحث.

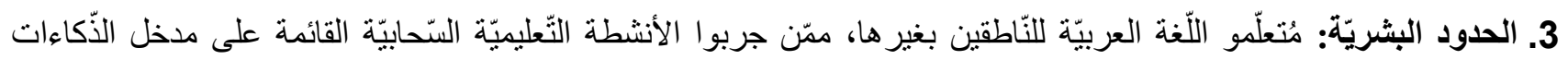
المتعدّدة في أثناء تعلّمهم اللّغة العربيّة سحابيًا في مركز "تعلّم العربيّة مع نور LEARN ARABIC WITH NOOR".

\section{• مصطحات البحث وتعريفاته الإجرائيّة}

1. التّصوّرات اصطلاحًا: "اعتقاد أو قول يرتبط بالتّضيلات والقيم والأذواق الثَّخصيّة ولا يخضع لمعايير الكّحة والخطأ والاستدلال." (شحاته، والنّجار، 2003، ص186). أمّا إجرائيًا، فهو الاعتقادات الني يحملها متعلّمو اللّغة العربيّة النّاطقين بغيرها حول الأنشطة التَّليميّة الستحابيّة القائمة على مدذل الذّكاءات المتعدّدة وفقًا لإجاباتهم عن فقرات الاستبانة المُشتخدمة في هذا البحث على مقياس ليكرت الخماسي.

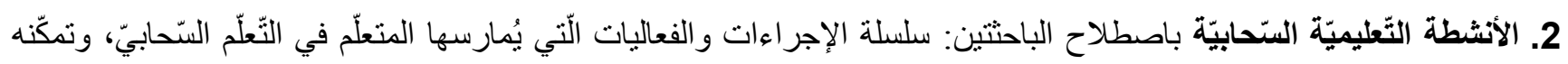
من الحصول على النّاتج التّعليميّ الَّي سعت إليه الأهداف تحت إثراف المعلّم. أمّا إجرائيًا، فهي إجراءات أنثطة (الذّكاء اللَّغويّ

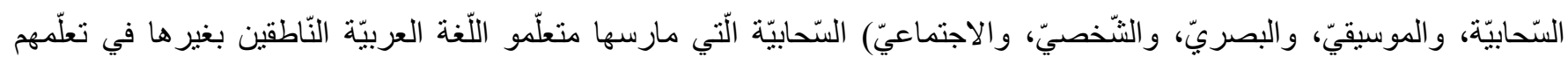
السّحابيّ في مركز "تعلّم العربيّة مع نور LEARN ARABIC WITH NOOR" بإشر اف المعلّم. 3. الذّكاءات المتعدّدة اصطلاحًا: "نموذج معرفي يصف الكيفية التي يستخدم بها الأفر اد ذكاءاتهم في حلّ المشكلات، وتقوم على تعدّد الذّكاءات: اللَّويّ، والرياضيّ، و الثَّضصيّ، والاجتماعيّ، و الموسيقيّ، والحركيّ، والمكانيّ، و الطبيعيّ." (جاردنر، 2004، ص28). • الإطار النّظريّ

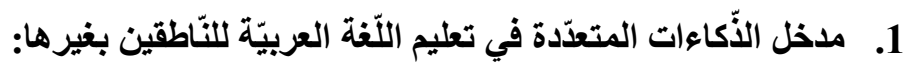

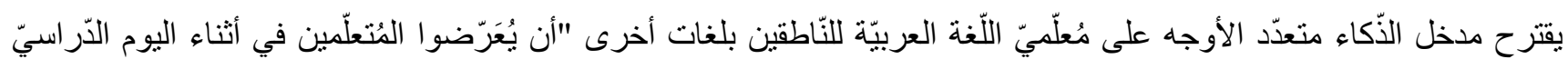
لأنشطة ومشاريع وبرامج تركز على تطوير أنو اع الذّكاء لديهم." (نوفل، 2007، ص297). فكلما "زاد عدد الذّكاءات التي يُخاطبها الذّرس أصبح التُعلّم أعمق وأثنمل" (عرفة، 2014، ص194)؛ أيّ التوسع في الأنشطة التعليميّة بما يقابل التعدّدية في الذّكاءات؛ لأنّ ذلك يُساعد المتعلّمين على إتقان اللّغة العربيّة، وخلق بيئة صفيّة مثيرة، تتضمّن أنشطةً و أدوات تقييم تتناسب وذكاءاتهم المختلفة. 
أنواع الذّكاء مُتعدّد الأوجه وأنشطته: ثُمّة أنواع متعددّة للذّكاء؛ إذ قد انفتح مفهوم الذّكاء ليشمل العديد من القدرات التّي كانت قبل نلك خارجه. هذه الأنواع، هي:

الذّكاء اللّفويّ (اللّفظيّ): إنّ الذّكاء اللّغويّ قدرةٌ على امتلاك اللّغة والتمكن من مهار اتها، واستخدام مفرداتها اللّغوية بطلاقة في التعبير شفهيًا (روايـة الحكايـات والخطابة)، وكتابيًا (الشُعر، والتأليف القصصّي و المسرحي، ومختلف ألـوان الكتابة). وفهم مادتها اللّفظيّة وتحليلها، و إدر الك المجاز فيها و الاستعارة. ويتمثل في "القدرة على معالجة البناء اللّغويّ، والصوتيات، والمعاني، والاستخدام العمليّ للّغة، الذي قد يكون هدفه: البلاغة أو البيان: استخدام اللّغة لإقناع الآخرين بسلوك معين أو التذكر : استخدام اللّغة لتذكر معلومات معينة، تتر اوح بين قوائم الممتلكات، وقو اعد لعبة ما، وإرشادات أو التوّيح: استخدام اللّغة لإيصال معلومات معينة أو استخدام اللّغة لتتحدث عن نفسها (ما بعد اللّغة).

من أنثطته: المناقثنات في مجموعات صغيرة أو كبيرة، والألعاب المعتمدة على الكلمة، وسرد القصّص، و المحاضر ات و الندوات، و القر اءة الجهرية، و العصف الذّهني، وسرد القصص، واسترجاع وحفظ الحقائق اللّغويّة، والتسجيل الصّوتي، وكتابة البوميات، والإذاعة، و المشاركة في المنتدى الثقافي، و الألغاز ، وقراءة الكتب في المكتبة، و إعداد تقارير صحفيّة، و إنتاج مواد أدبية أو ثقافية، وكتابة بطاقة اعتذار، ومحضر اجتماع، وبطاقات دعوة، واستعمال المعجم، والاستفادة من المصادر والمر اجع، والخطابة، والمناظر ات.

الأّكاء المكانيّ (البصريّ): إنّ الذّكاء البصريّ قدرة على إدراك العالم البصري المكاني بدقة، والتفكير في حركة ومواضع الأشياء في الفر اغ، والقدرة على إدرالك صور أو تخيلات ذهنية داخلية. ويتمثل في الحساسية للألوان، والخطوط، و الأشكال، و الحيز، و العلاقات بين العناصر، والقدرة على التصوّر البصريّ والتمثيل الجغر افيّ للأفكار ذات الطبيعة البصرية أو المكانية، وتحديد الوجهة الذاتية على نحو مناسب في مصفوفة مكانية دقيقة. وتمثيل الأفكار البصرية أو المكانية بيانيًا.

من أنشطته: الرسوم التوضيحية، والصّور، و الخر ائط، والخرائط المفاهيميّة، والأنشطة الفنيّة، مثل: المعارض والمتاحف، والتخيّل الموّجه، وأحلام اليقظة، و الرّسم والأشغال، و التصوير، والزخرفة، والخط العربي، وتصميم الملصقات، والرسوم الكرتونيّة (الكاريكاتير) )، و ألعاب الذّاكرة، و القصص المصوّرة، والعروض البصرية (الفيديو).

الأّكاء الموسيقيّ (الإيقاعيّ): إنّ الذّكاء الموسيقيّ حساسية لاتساق الأصوات، والألحان، والأوزان الثعرية، وتعيين درجة النغم أو طبقة الصوت، والتناغم. ويتمثل هذا الذّكاء في الفهم الحدسيّ الكنّيّ للموسيقى، أو الفهم التحليلي الرسمي لها، أو الجمع بين هذا وذات، و التعبير الموسيقي نقدًا، وتأليفًا، وعزفًا، وتمبيز طبقات الصوت والإيقاع، ودرجة النغمة. 
من أنشطته: الغناء، والهمهة،، والتصفير، و ابتكار ألحان جديدة للمفاهيم والكلمات، وتكوين أنماط ذات قافية، والموسيقى كخلفيّة للموقف التعليميّ، و الإيقاعات، وجمع الأسطو انات وتصنيفها، و المسرح الغنائي، والألعاب التي تقوم على التصفيق، والعزف على الآلات الموسيقيّة العربيّة، واستخدام التسجيلات الصوتيّة، و الأغاني و الأناثشيد، والإلقاء المعبر، و العروض وموسيقى الشعر.

الأّكاء الاجتماعي (البين شخصيّ): إنّ الذّكاء الاجتماعي قدرةٌ على فهم اتجاهات الآخرين، ودوافعهم والتمييز بينها؛ من أجل التصرف بحكمة حيالها وفعالية. و إدراك العلاقات الاجتماعية بغية إقامة علاقات ناجحة مع الآخرين. ويتمثل في القدرة على إدراك أمزجة الآخرين ومقاصدهم ودو افعهم ومشاعر هم و التمييز بينها، و الحساسية لتعبيرات الوجه والصّوت والإيماءات، والقدرة على التمييز بين الأنو اع المختلفة من الثّخصيات، و القدرة على العمل التعاوني. من أنشطته: التفاعل بين الأفر اد، ومشاركة الأقران، و المناقثات الجماعية، والعمل التعاوني، ولعب الأدو ار، و المساجلات، و الألعاب الجماعية، و العمل التطوعي.

الذّكاء الثَّصيّ (الذاتيّ): إنّ الذّكاء الثّخصي قدرةٌ على فهم الذات من خلال إدراك مشاعرها، وأحلامها، وتنظيم علاقاتها مع الآخرين. وتعرّف مكامن القوّة والضّعف لايها في اتخاذ القرار المعتمد على حاجاتها ومشاعر ها وأهدافها الذّاتية. ويتمنل في القدرة على التأمل الدقيق للقدر ات الإنسانية وخصائصها ومعرفتها.

من أنشطته: البر امج والأعمال والألعاب الفردية، وأنشطة تقدير الذّات، والتعلّم حسب سر عة الفرد، وكتابة المذكرات، وفترات التأمل لمدة دقيقة، والروابط الثَّحصيّة، واللّحظات الانفعالية، وإعداد المقابلات، وإنتاج مواد أدبية أو صحفية أو نقافية، والقراءة الذاتيّة.

\section{2. العلاقة بين مدخل الذّكاعات المتعدّدة والأنشطة التّعليميّة الستحابيّة:}

من المجالات التّي تنمّيها الأنشطة التّعليميّة النّحابيّة القائمة على مدخل الذّكاءات المتعدّدة في تعليم اللّّة العربيّة للنّاطقين بغير ها من وجهة نظر الباحثتين، الآتي:

إثر اء المعجم اللّغويّ: هناك زخم مفرداتيّ وتركيبيّ يوسّع الحقل اللّغويّ لدى المتعلّم.

فهم الثّقافة بتعرّف مجتمع اللّغة الهدف بمصادر متعدّدة دون مغادرة الصّف ما يجعل تعلّم اللّّة جزءًا من التّجربة الثّقافيّة. إغناء المهار ات اللّغويّة كافّة بتفاعلها في الأنشطة معظمها. تقدّم القو اعد في سياق، فتمثّل بذلك أرشيفًا للاستخدام اللّغوي. تقديم النّموذج؛ أمثلة للكلام الجيّد، والتّوّع في الأساليب اللّغويّة، و النّطاقات التّببيريّة. 
إضفاء المتعة إذ يؤدّي استخدامها إلى إدخال عنصر التّلية على العملّية التّعليميّة.

توفير سياق أصيل يعكس استخدام اللّخة الحقبقيّ ممّا يعزّز الدّافيّيّة لدى المتعلّمين.

$$
\text { الاستدلال على مو اضع النّبر و التّنغيم. }
$$

توظيف لغة الجسد.

المعلومات؛ فهناك محتوى معرفيّ كبير ومتنوّع تنوّع الحاجات.

الغنى بالأدوات التّي تسهّل تعلّم مهارات اللّغة الأربع، مثل: الصّور، والمواد المسموعة والمرئيّة، و البث الإذاعيّ، ومؤتمرات

$$
\text { الفيديو، و المحادثات الفوريّة، و البر امج، و المو اقع، و الكتب... }
$$

التّوع في الأساليب، مثل: المجمو عات التّعاونيّة أو المشاريع الفرديّة ما يعزّز مهار ات التّكير وحلّ المشكلات. تحرير المحتوى من قيود الزّمان والمكان و المساحة ممّا يسمح باستعر اضه تبعًا للفروق الفرديّة في المستوى اللّغوي، والخجل،

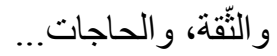

التّفاعليّة عندما تعطي ردود فعل و إجابات فوريّة وتصحيحًا مباشرًا للمستويات المبتدئة وتفاعلًا متبادلًا في اللّحظة نفسها (تز امنيًا) أو

$$
\text { لاحقًا (غير نز امنيّ) ممّا يشّجع على الاندماج. }
$$

الجاذبيّة بأسلوبها الَّي يتناسب و العصر الَّبي نعيش فيه.

• منهج البحث

اتُّبع المنهج الوصفي؛ لـُناسبته طبيعة موضوع البحث.

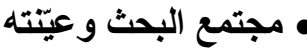

متعلّمو اللّغة العربيّة النّاطقين بغيرها هم مجتمع البحث. أمّا عيّنته، فاقتصرت على (33) متعلّمَا ومتعلّمة ممّن يتعلّمون العربيّة في مركز "تعلّم العربيّة مع نور LEARN ARABIC WITH NOUR" سحابيًا، وجرّبوا الأنشطة التّعليميّة السّحابيّة القائمة على مدخل الذّكاءات المتعدّدة.

\section{• أدوات البحث}

اقتصر البحث على استبانة تصوّرات مُتعلّمي العربيّة النّاطقين بغير ها حول الأنشطة التّعليميّة السّحابيّة القائمة على مدخل الذّكاءات 
بعد مُراجعة الأدبيات والبحوث العلميّة المُشابهة لموضوع البحث، جرى تحديد مجالات الأداة بالذّكاءات الآتية: الذّكاء اللّغويّ السّحابيّة، و الموسيقيّ، والبصريّ، والثّخصيّ، والاجتماعي. واشتملت على (42) فقرة في كلّ منها نشاط سحابيّ قائم على ذكاء محدّد على أنّ بعضها قد يتداخل في أكثر من ذكاء، ومقياس ليكرت الخماسي (مرتفعة جدًا/، ومرتفع / /، ومتوسط / /، ومنخفض / /، ومنخفض جدًا)؛ لتقدير درجة التّصوّر. وصَدّرت بمقدّمة وتعليمات للمتعلّم لبيان كيفّة الإجابة. ترجمت إلى الإنجليزيّة كونها اللّّة المشتركة بين أفراد عيّنة البحث، وطبّتت عليهم بنماذج جوجل (google form).

\section{صدقها}

عرضت الأداة على مجموعة من المحكّمين (صدق المحتوى) في تعليم اللّغة العربيّة للنّاطقين بغير ها، وتقنيّات التّعليم، و القياس و الثّقويم؛ لإبداء وجهة نظر هم واقتر اح أو حذف أو تعديل ما يرونه مُناسبًا. فأبدوا ملاحظات، منها: اختصار الأنشطة السّحابيّة لتصير على صورتها الحاليّة، وتعديل صياغة بعض العبارات غير الواضحة، وتدقيق بعض العبارات لغويًا، وملاحظات على التّرجمة؛ ذلك ليتمكّن المتعلّمون من الإجابة عن فقر اتها على نحو أفضل.

ثباتّها

جرى حساب معامل ثبات الاختبار بطريقة الاتّساق الدّاخليّ بدلالة الفقرة باستخدام معاملة ألفا كرونباخ، وتبيّن أنّها بلغت

$$
\begin{aligned}
& \text { (0.98\%)؛ و هي معاملات ثبات جيّة ومناسبة لأغر اض البحث العلميّ. } \\
& \text { • نتائج البحث }
\end{aligned}
$$

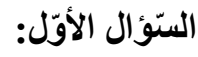

ما تصوّرات متعلّمي اللّفة العربيّة النّاطقين بغيرها نحو الأنثطة التّعليميّة السّحابيّة القائمة على الذّكاء اللّفويّ، والموسيقيّ، والبصريّ، والثَخصيّ، والاجتماعيّ

أجريت للإجابة عن هذا السيّؤال المعالجات الإحصائيّة الآتية، هي: المتوسّط الحسابيّ، والانحراف المعياريّ، والنّسب المئويّة. وجاءت النّتائج على النّحو الآتي: 


\section{جدول(1): المتوسيّطات الحسابيّة والانحر افات المعياريّة والنّسب المئويّة}

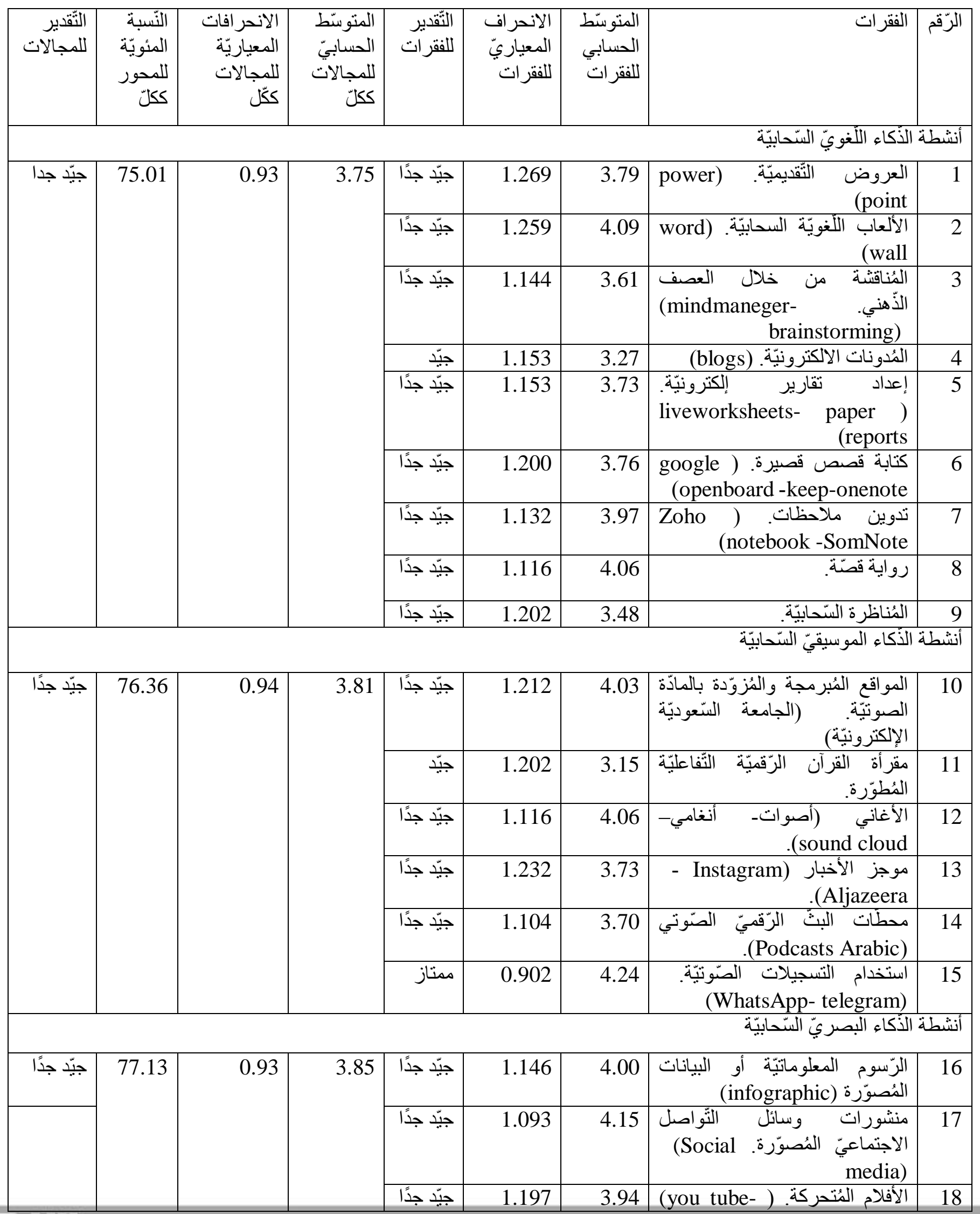




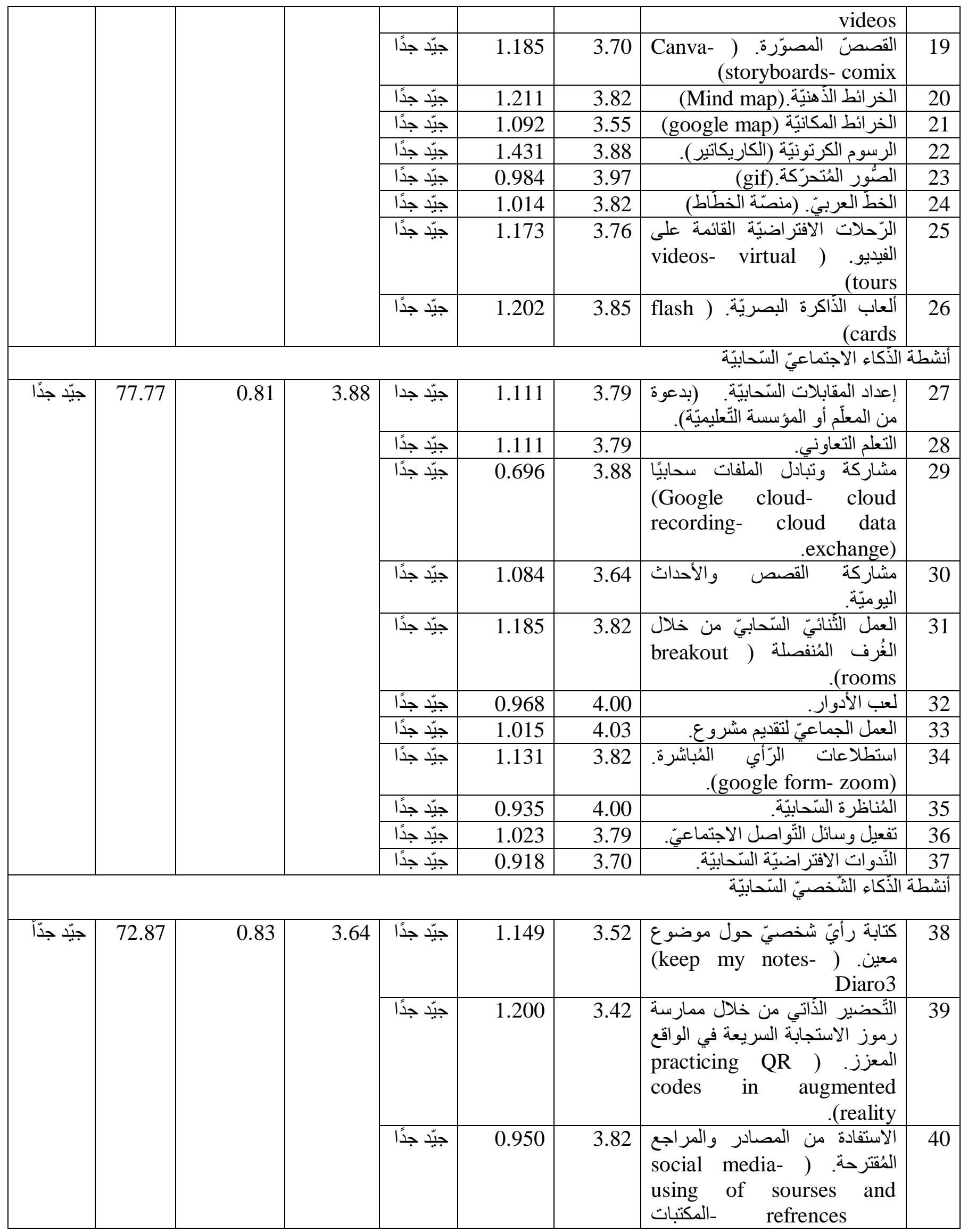




\begin{tabular}{|c|c|c|c|c|c|c|c|}
\hline & & & & & \multicolumn{3}{|c|}{ الإلكترونيّة) } \\
\hline & & جيّد جدًا & 0.975 & 3.78 & & أنشطة المُحاكاة. & 41 \\
\hline & & جيّد جدًا & 1.070 & 3.88 & الآلّر اسات. & 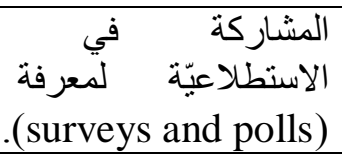 & 42 \\
\hline جيّد جدًا & 76.14 & & & & & & \\
\hline
\end{tabular}

النّيجةة: يتبيّن من الجدول (1) أنّ تصوّرات المتعلّمين (إيجابيّة)، وبدرجة (مرتفعة) على مجالات الأنشطة جميعها؛ إذ بلغت النّسبة المئوية للتّصوّر الكتّي (75.92\%). فكانت أعلى نسبة لأنشطة الذّكاء الاجتماعيّ السّحايّة (77.74\%)، فالبصريّة (77.13\%)، فالموسيقّة (76.36)، فاللّغويّة (75.09)، فالثّخصيّة (73.57\%). وبينت أن نشاط الألعاب اللّغوية الصّوتيّة حاز أعلى نسبة، فقد بلغ (84.84\%) ثم أنشطة وسائل التو اصل الاجتماعي (83.03\%)، ثم الألعاب التّعليميّة (81٪). أمّا أقل الأنشطة فهو أنشطة الواقع المعزّز (68.48\%)، فاستخدام المدوّنات (65.45)، فأنشطة مقرئ القرآن التّقاعلي (63٪).

التّفير: تعزو الباحثتان هذه النّتائج لكون الأنشطة التّعليميّة السّحابيّة تقدّم المحتوى اللّغويّ والثّّافيّ على نحو مشوق، وجذاب يجعل المتعلّمين إيجابيين في فهمه؛ وفي تنوّعها مراعاة للفروق الفرديّة بين المتعلّمين. إضافة إلى أنّها تنمّي الأداء اللّغويّ عبر أنشطة الذّكاء اللّغويّ، أمّا غير اللّغويّ فيمكن عبر المحاكاة بأنشطة الذّكاء البصريّ. علاوة على أنّ ذلك تعزّز مهارات النّّ اصل لديهم بأنشطة الذّكاء الاجتماعيّ؛ إذ تعتمد على نشاط المُتعلّم، وإظهار قدر اته اللّخويّة، والحركيّة، و الثّّخصيّة على أنّ ذلك يكون محدودًا بسبب طبيعة التّعليم السّحابي. أيضًا، تزيد أنشطة الذّكاء اللّغويّ و البصريّ رصيد المتعلّم اللّغويّ من المفردات والتّر اكيب؛ ذلك أنّها تقدّم نماذج لغويّة سليمة يمكن محاكاتها. هذا من شأنه تتمبة مهار ات الصّحة و المفردات والطّلاقة. كذلك الأنشطة النّي تقدّم النّصوص القصّصيّة على نحو بصريّ أو سمعيّ أو مرئيّ ضمن أنشطة الذّكاء البصريّ والموسيقيّ حين تخاطب حواس المتعلّم كافة تجعل أثر التّعلّم أبقى وأظهر. وعندما يُقدِمُ المُتعلّمون على المشاركة بكلّ هذه الأنشطة بما يتوارد لهم؛ قد تُحلّ مشكلات نفسيّة واجتماعيّة لديهم، مثل: الانطو اء، والخجل، وضعف الثّقة بالنّفس ممّا بدعم مهارات الطّلاقة أيضًا. كذلك تضفي الأنشة السّحابيّة على الموقف التّعليمي المرح؛ فينكسر جمود الموقف التّو اصليّ ممّا يجعل المهار ات اللّغويّة تجري على نحو أفضل. كما أنّ مناسبة الأنشطة لكلّ نمط ذكاء توفّر أجواء مريحة لاستخدام اللّّة، فتساعد على إثارة الذّافعية، وتحفّز على التّعلّم. أيضًا، بالنّسبة إلى أنشطة الذّكاء اللّغويّ؛ فالأسئلة التي بطرحها المُعلّم تساعد على استرجاع المعلومات المحفوظة في الذّاكرة، وتثبّت المعارف التي استوعبها المتعلّمون في غبر هذه المهارة ممّا يعزّز مهارات الطّلاقة و المضمون و المفردات و التّر اكيب و الصّحة لديهر.

الأنشطة في الذّكاءات معظمها في جوهر ها قائمة على مركزية المتعلّم؛ إذ نتاح للمُتعلّمبين جميعهم؛ ممّن لديهم فكرة ما أنّ يحصلوا على تقدير واعتراف بأفكار هم الخاصّة خلال الأنشطة السّحابيّة في الذّكاءات كلّها الّتّي يجريها المعلّم ممّا يعزّز مهاراتهم في اللّّة 


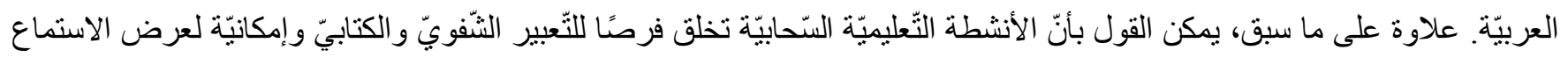
ونصوص القراءة على نحو ير اعي الفروق الفرديّة بين المتعَّمين.

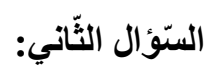

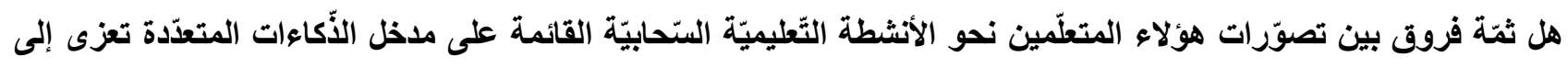
متغيّر الجنس؟

أجريت للإجابة عن هذا السيّؤال المعالجات الإحصائيّة الآتية، هي: اختبار test، والمنوسّطات الحسابيّة والانحرافات المعياريّة.

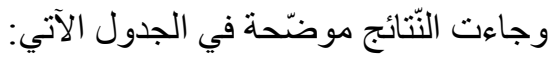

جدول(2): اختبار test والمتوستّات الحسابيّة والانحرافات المعياريّة

\begin{tabular}{|c|c|c|c|c|c|}
\hline 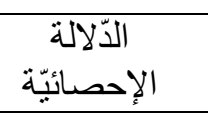 & 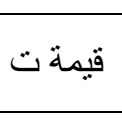 & الانحراف المعياريّ & الحستوسيّ الحيّ & 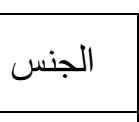 & 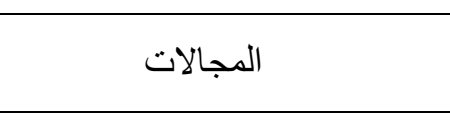 \\
\hline 0.25 & \multirow{2}{*}{1.17} & 0.94 & 3.92 & إناث & \multirow{2}{*}{ أنثنطة الذّكاء اللّغوي السّحابيّة } \\
\hline غير دال & & 0.89 & 3.54 & ذكور & \\
\hline 0.18 & \multirow{2}{*}{1.37} & 0.91 & 4.01 & إناث & \multirow{2}{*}{ أنثشطة الذَكاء المو سيقيّ السّحابيّة } \\
\hline غير دال & & 0.96 & 3.56 & ذكور & \\
\hline 0.09 & \multirow{2}{*}{1.76} & 0.97 & 4.10 & إناث & \multirow{2}{*}{ أنثططة الذّكاء البصري السّحابيّة } \\
\hline 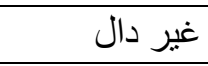 & & 0.82 & 3.53 & ذكور & \\
\hline 0.17 & \multirow{2}{*}{1.40} & 0.78 & 4.05 & إناث & \multirow{2}{*}{ أنشطة الذّكاء الاجتماعيّ السّحابيّة } \\
\hline غير دال & & 0.71 & 3.67 & ذكور & \\
\hline 0.24 & \multirow{2}{*}{1.19} & 0.89 & 3.83 & إناث & \multirow{2}{*}{ أنثشطة الذّكاء الثَّخصيّ السَّابيّة } \\
\hline 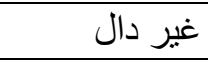 & & 0.82 & 3.47 & ذكور & \\
\hline 0.15 & \multirow{2}{*}{1.48} & 0.87 & 3.98 & إناث & \multirow{2}{*}{ المجالات جميعها } \\
\hline غير دال & & 0.79 & 3.55 & ذكور & \\
\hline
\end{tabular}

النّيجة: يظهر الجدول (2) أنّ ليس هناك فروق ذات دلالة إحصائيّة تعزى إلى متغيّر الجنس.

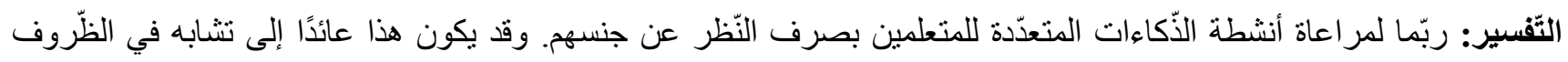
الاجتماعيّة و التعليَّمَّة للمتعلَمبين وتقارب في التطلّعات نحو تطوير مهارات اللَّغة العربيّة. 


\section{مقترحات البحث}

1. التركيز على وظيفيّة الأنشطة السّحابيّة، وربطها بواقع مُتعلّميّ اللّنة العربيّة النّاطقين بغير ها، استنادًا إلى ميولهم واهتماماتهم؛ لأنّ ذلك يثير دافعيتهم نحو تعلّم اللّّة.

2. الإفادة من نتائج هذا البحث؛ بإحداث تغييرات في مجال الأنشطة الموجهة لمُتعلّميّ اللّغة العربيّة النّاطقين بغير ها؛ باعتماد الأنشطة

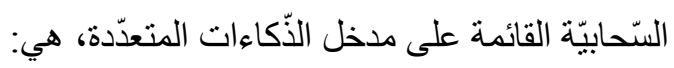

$$
\begin{aligned}
& \text { أنشطة الذّكاء اللّغويّ السّحايِّة. } \\
& \text { أنشطة الذّكاء الموسيقيّ السّحابيّة. } \\
& \text { أنشطة الذّكاء البصريّ السّحابيّة. } \\
& \text { أنشطة الذّكاء الثّخصيّ السّحابيّة. } \\
& \text { أنشطة الذّكاء الاجتماعيّ السّحابيّة. }
\end{aligned}
$$

3. إجر اء مزيد من الأبحاث المُماثلة حول الأنشطة السّحابيّة للذّكاءات الأخرى بأنواعها المُختلفة وبيان فاعليتها في المهارات اللّغويّة الأربع.

4. تدريب معلّمي اللّغة العربيّة للنّاطقين بغير ها على توظيف الأنشطة التّعليميّة السّحابيّة القائمة على مدخل الذّكاءات المتعدّة لإكساب وتنمية المهار ات اللّغويّة للمستويات كافّة؛ بإجر اء الورش و عقد النّدوات التّريفيّة وتوفير الأدلة الإرشاديّة.

\section{الملاحق}

استباتة تصوّرات مُتعلّمي العربيّة النّاطقين بغيرها حول الأنشطة التّعليميّة الستحابيّة القائمة على مدخل الأّكاءات المتعدّدة

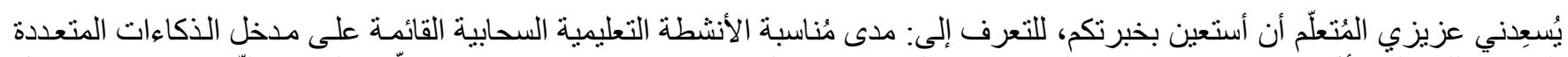

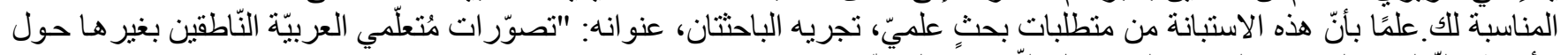

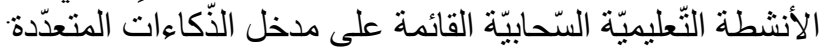

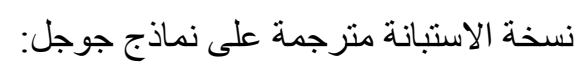

https://forms.gle/Xpqbo89eL4ED1TtVA 


\section{قائمة المراجع والمصادر:}

أبو عمشة، خالد، وأبو الوفا، عزت، وشنيك، هبة، العبيدي، بشير، فريحة، صابر، شر شابي، محمود، وجاموس، راوية. (2020).

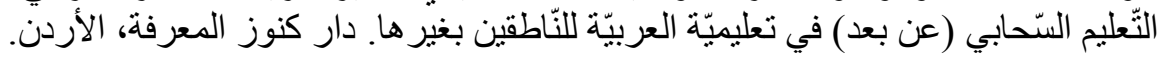

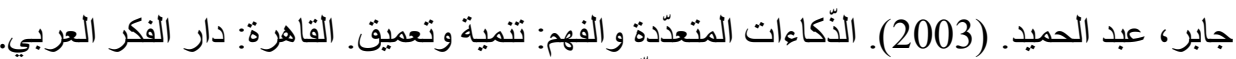
جاردنر، ه. (2004). أطر العقل: نظريّة الذّكاءات المتعدّدة. (محمد بلال الجيوسي: منرجم). الرياض: مكتب التربية العربي لدول الخليج.

حسين، نهى عبد الكريم. (2020). فاعلية القصّة الرّققيّة في تنمية مهارتي الكلام والكتابة لدى متعلمي اللّّة العربيّة النّاطقين بلغات

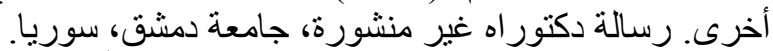

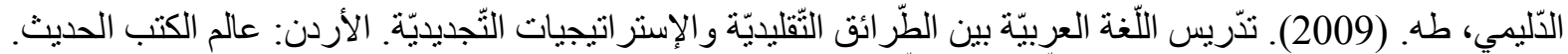

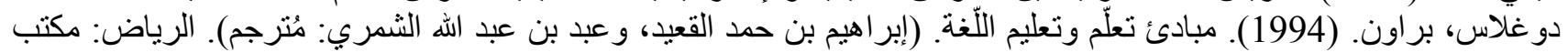
التربية العربية لدول الخليج.

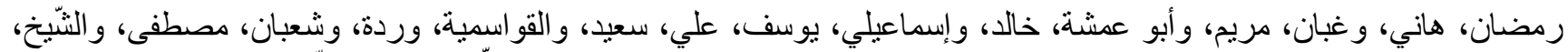

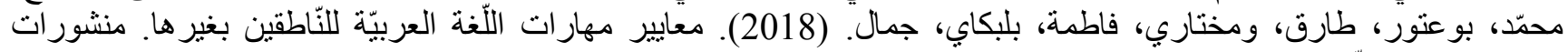
المنتدى العربي الثرّكي، تركيا.

رينتارد، جآكّ. (2005). تطوير مناهج تعليم اللّغة. (ناصر بن غالي، وصالح الثوير خ: منرجم). الرياض: جامعة الملك سعود.

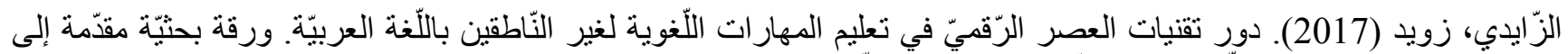

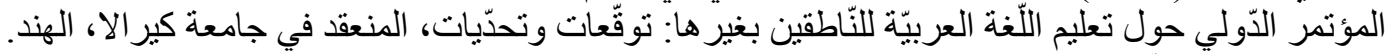

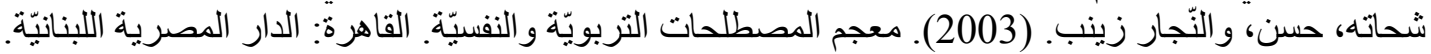

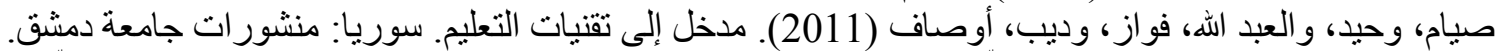

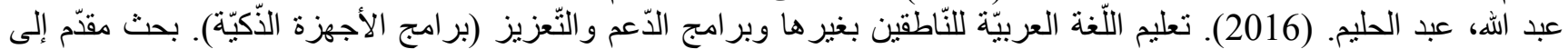

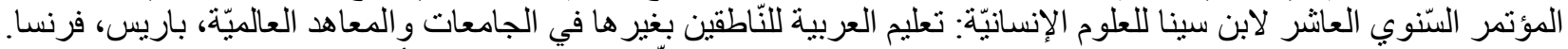

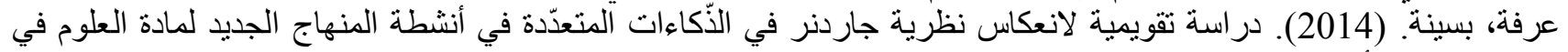

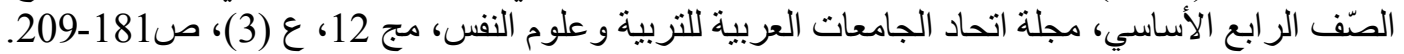
المنتدى الذّوليّ الافتر اضيّ للّخة العربيّة للنّاطقين بغير ها بعد كوفيد 19: تجديد الاستراتيجيات وتطوير الوسائل والمنهجيات (2020)،

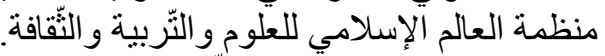
نوفل، محمد بكر. (2008). الذّكاء المتعدّد في غرفة الصّة الصّفة، النظرية والتطبيق. عمان: دار المسيرة. www.actfl.org.

Luoma, S. (2004). Assessing Speaking ( $5^{\text {th }}$ ed/2009). Cambridge: Cambridge University Press. Abdul-Khafaji, Adnan(2021). Common mistakes in drawing writing for students of Arabic of nonnative speakers, Arid International Journal of Educational and Psychological Sciences, VOL.2 NO.4, July(pp. 56-80). 